\title{
6. Defining innovation for measurement purposes
}

\subsection{INTRODUCTION}

The definition of innovation for measurement purposes has a long history. For OECD and EU countries a definition was agreed in 1992 when, after years of experimentation with innovation surveys, the knowledge gained was codified in the first Oslo Manual (OECD 1992). It dealt with product and process innovation in manufacturing. In 1997 (OECD/ Eurostat 1997) the manual was revised to include marketed services, construction and utilities, in addition to manufacturing (OECD/Eurostat 1997: para. 15). Product innovation remained the same, but process innovation had product delivery added to its definition.

Between the release of the second edition in 1997 and the third in 2005, there was an innovation project in Latin America and the Caribbean which led to the Bogotá Manual (RICYT/OEC/CYTED 2001). The manual focused on manufacturing and differed from the Oslo Manual in its treatment of local capabilities and capacity building and its discussion of organisational change and market development. This influenced the third edition of the Oslo Manual (OECD/Eurostat 2005) which added both organisational change and market development to the definition of innovation and an Annex, at the request of RICYT, on interpreting the manual for use in innovation surveys in developing countries (OECD/Eurostat 2005: 135). This was a step towards making the Oslo Manual accessible globally. Another step, in the third edition, was the chapter on linkages. The innovation activities of a firm depend on links to sources of information, knowledge, technologies, practices and human and financial resources. In a systems approach (Chapter 2) to the measurement of innovation, linkages matter more than firms. Linkages, such as value chains, and their impacts, tend to be different in developing and developed countries. 
A common characteristic of the first three editions of the Oslo Manual is that they all provide guidance for measuring firm-level innovation in the business sector. This is not surprising as innovation in the business sector is seen as a primary source of wealth creation and economic growth. With each edition, the sector coverage broadened, and the third edition included innovation in the entire business sector (OECD/Eurostat 2005: para. 27). This was the first appearance in the Oslo Manual of primary industries (agriculture, forestry, fishing and mining).

Starting from manufacturing and moving through three editions to the entire business sector was a natural progression resulting from learning by doing and responding to policy needs that did not deal only with manufacturing. A second progression, still evolving, followed the first OECD Blue Sky Forum in 1996. It was the growing emphasis on a systems approach to measuring innovation. A third progression was the recognition that innovation did not happen only in the business sector. The first and second editions of the Oslo Manual noted that 'Innovation can of course occur in any sector of the economy, including government services such as health or education' (OECD 1992: para. 84; OECD/ Eurostat 1997: para. 15). The same statement appeared in the third edition with a minor change ('of course' was dropped) (OECD/Eurostat 2005: para. 27). However, motivated by findings from measuring innovation in other sectors (Gault 2018a), the fourth edition provided a general definition of innovation applicable in all economic sectors. This was a major step in defining innovation for measurement purposes. The fourth edition of the Oslo Manual (OECD/Eurostat 2018: para. 102) makes the point that:

specific innovations can involve the participation of multiple actors across sectoral boundaries. These units can be linked through various methods, such as funding mechanisms, hiring of human resources, or informal contracts.

This is discussed further in Section 6.2.

In parallel with the work on innovation in all sectors, policy developers were showing interest in 'restricted' forms of innovation (Gault 2018a). In the business sector, surveys could be conducted according to Oslo Manual definitions, using a statistical sample, and identifying a sample population of innovative firms. This would provide the basis for a population estimate of the propensity to innovate. What it did not provide was information on whether the innovation was sustainable, inclusive, pro-poor, green or any combination of those or any other constraints 
that were important to policy makers. Dealing with this is discussed in Section 6.3.

Deciding not to have an Annex interpreting the manual for use in developing countries in the fourth edition was noted as a step towards a global manual. In the fourth edition the whole manual was accessible to developing and developed countries. This brought the Oslo Manual into line with the System of National Accounts, 2008 (2008 SNA) (EC et al. 2009: para. 1.4) where it is noted that:

There is no justification, for example, for seeking to define parts of the SNA differently in less developed than in more developed economies, or in large relatively closed economies than in small open economies, or in high-inflation economies than in low inflation economies.

Just as innovation does not happen in isolation, neither does the development of an innovation manual. In parallel with the work leading to the fourth edition of the Oslo Manual, the International Organization for Standardization (ISO) was developing a definition of innovation for the purpose of innovation management in its ISO 56000 series. To ensure compatibility, OECD and ISO worked closely together during the period of revision (Gault and Hakvåg 2018). This is discussed in Section 6.6.

\subsection{DEFINITION OF INNOVATION IN THE OSLO $M A N U A L$}

The fourth edition of the Oslo Manual has two definitions of innovation: a general definition applicable in all economic sectors and a sector-specific definition for the business sector. B Both are presented and then there is a discussion of the measurement implications of the two definitions.

The general definition of innovation in the fourth edition of the Oslo Manual is the following.

An innovation is a new or improved product or process (or combination thereof) that differs significantly from the unit's previous products or processes and that has been made available to potential users (product) or brought into use by the unit (process). (OECD/Eurostat 2018: Chapter 1, para. 1.25, Chapter 2, para. 2.99)

The definitions of sectors are those of the SNA (EC et al. 2009). 'Unit', in the general definition, refers to the 'institutional unit' in the sector and 
examples are provided in Chapter 7 of this book. In the business sector, the 'institutional unit', or 'unit', is the firm.

In principle, the general definition could be applied to all sectors including the business sector. However, the Oslo Manual has, from its beginning in 1992, been a manual for collecting, reporting and using data on innovation in the business sector where a product innovation is introduced on the market and a process innovation is brought into use. This has continued in the fourth edition. The definition of innovation in the business sector is close to that in the third edition, allowing continuity in innovation surveys, including the EU Community Innovation Survey (CIS), which has been conducted since 1992. From 2006, CIS has occurred in EU Member States, and other states, every two years.

The definition of business innovation is:

A business innovation is a new or improved product or business process (or combination thereof) that differs significantly from the firm's previous products or business processes and that has been introduced on the market or brought into use by the firm. (OECD/Eurostat 2018: Chapter 3, para. 3.9)

The definitions of innovation in the third and fourth editions of the Oslo Manual are similar. This has the advantage that statistics gathered through surveys based on the Oslo Manual require little additional guidance of respondents. The similarity is illustrated in what follows.

The definition of innovation in the third editions is:

An innovation is the implementation of a new or significantly improved product (good or service), or process, a new marketing method, or a new organizational method in business practices, workplace organization or external relations. (OECD/Eurostat 2005: para. 146)

For the definition to be complete, 'implementation' must be defined. The definition of 'implementation' is found in the following:

A common feature of an innovation is that it must have been implemented. A new or improved product is implemented when it is introduced on the market. New processes, marketing methods or organisational methods are implemented when they are brought into actual use in the firm's operations. (OECD/Eurostat 2005: para. 150)

Comparing the third and fourth edition definitions, they are the same for product innovation. In the case of a process innovation, the third edition has three functional categories, the fourth edition has six (OECD/ 
Eurostat 2018: Table 3.1). The correspondence of the three categories in the third edition to the six categories in the fourth edition is more indicative than precise, but the advantage of the six is that they support better measurement of the innovation process. The categories follow.

The first category of the third edition is 'process innovation', the implementation of a new or significantly improved production or delivery method (OECD/Eurostat 2005: para. 163). In the fourth edition, two categories are used: 1. Production of goods and services and 2. Distribution and logistics.

The second category in the third edition is marketing innovation, the implementation of a new marketing method involving significant changes in product design or packaging, product placement, product promotion or pricing (OECD/Eurostat 2005: para 169). This corresponds in the fourth edition to the category: 3 . Marketing and sales.

The third category in the third edition is organisational innovation (OECD/Eurostat 2005: para. 177), where an organisational innovation is the implementation of a new organisational method in the firm's business practices, workplace organisation or external relations. The closest correspondence in the fourth edition is: 5. Administration and management. There are two other categories in the fourth edition: 4 . Information and communication systems and 6. Product and business process development.

Turning to the fourth edition definition, the only difference of substance between the definition of business innovation and the general definition is 'made available to potential users' for a product compared with 'introduced on the market'. The consequences of using the general definition in the business sector are explored in Section 6.4 and in Chapter 7. It appears here in a chapter on definitions because of the presence of the digital economy and the implications the digital economy has for definitions of innovation.

\subsection{RESTRICTED INNOVATION AND MEASUREMENT}

The Oslo Manual provides guidelines for collecting, reporting and using data on innovation. It does not deal with restrictions on the type of innovation to be measured or on its outcomes. Examples already mentioned are sustainable innovation, inclusive innovation, green innovation and pro-poor innovation. There are others. 
With a growing policy interest, there is a need for measurement of restricted innovation in order to support monitoring and evaluation of policies designed to promote the restricted innovation. However, in most cases, the desired objective of sustainability or inclusion cannot be determined by one measurement. The first measurement serves to provide a baseline, but others must follow to confirm that the result of the innovation is sustainable, or that the excluded population is included. Where people, and their lives, are concerned the subsequent measurements may include social as well as business surveys.

Also, for the measurement to be successful there must be a definition of 'sustainable' or 'inclusion', as well as for any other term used to restrict the innovation. The time interval, or intervals, to confirm that the object is achieved must also be agreed.

An example of restricted innovation dealing with sustainability and inclusion is provided by Mashelkar $(2012,2014)$ :

Inclusive innovation is any innovation that leads to affordable access of quality goods and services creating livelihood opportunities for the excluded population, primarily at the base of the pyramid and on a long term sustainable basis with a significant outreach.

In this definition, 'any innovation' links to the Oslo Manual definition of innovation and the restrictions follow, along with at least two time scales, the initial measurement and a subsequent one to confirm sustainability and other restrictions in the definition.

This example is discussed at greater length in Gault (2014, 2018a), which leads to a fundamental question: Are governments willing to pay for the new indicators that are needed to monitor and evaluate the relevant innovation policies?

Sustainability requires measurement over at least one time period to demonstrate that the objective, however defined, has been achieved. Inclusion, again depending on how it is defined, can be built into the innovation process. A government procurement call, for example, could require that firms that apply have a labour force with at least a specified percentage of the excluded population. However, in such a situation, firms that met the requirement some time ago could apply and others not. The policy objective of increasing the employment opportunities for the excluded population would not be achieved. This is discussed further in Chapter 9. 
A final point on the definitions of innovation in this chapter is that they include no moral or ethical conditions. Nowhere is there an assumption that innovation is good, or bad. As discussed above, the definition of innovation can be restricted to deal with inclusive, social or sustainable innovation, the restricted definition must still support statistical measurement through surveys or other means of data collection, leading to indicators which can be used to support policy development, and the monitoring and evaluation of implemented policy. To make this happen, the terms used in the restricted definition must be defined.

However, definitions do not always support statistical measurement. Definitions can also be used to guide discussion and theorising, and this is an important means of developing a subject. The measurement approach and the theorising approach are not at variance but are complementary.

\subsection{DIGITAL ECONOMY, INNOVATION AND MEASUREMENT}

The digital economy is everywhere and so is innovation. The general definition of innovation in Section 6.2 is applicable in all the economic sectors (discussed in Chapter 7), including the business sector. The discussion starts with product innovation in the business sector but uses the general definition.

The general definition imposes two conditions on a product for it to be a product innovation. The product

- is new or improved and differs significantly from the unit's previous products and

- has been made available to potential users.

Nowhere is the product required to be sold at economically significant prices, it needs only to be 'made available to potential users', and to have satisfied the first condition. The product can be given away. This raises a question about why any firm would give away a product.

There are many cases where products are provided to potential users at zero price. These include email accounts, cloud services and apps. They may be given freely to potential users, but there is an expectation that the producer is connected to the user allowing the producer to follow what the user is doing. This may seem like a barter transaction, but how many users think of it this way? The rationale is that the service provided is improved if information on transactions, processing and searching can 
be collected and used by the producer. This suggests that, in a digital economy, with digital products at zero price, there is a de facto third condition. The product connects the user to the producer.

This is not found in the Oslo Manual, but it provides a basis for examining zero price product innovations and their impact on users. Users are not just households and individuals, but actors in all economic sectors of the SNA. This will be discussed in Chapter 7.

The policy implications of digital innovation are discussed in Chapter 10 (OECD 2019a, 2019d).

\subsection{OSLO MANUAL DEFINITIONS AS INTERNATIONAL STANDARDS}

In the introduction to this chapter, there was reference to the Oslo Manual becoming an international standard. The fourth edition is designed to be accessible to developing countries as well as to the 36 OECD Member Countries, observer countries and 28 EU Member States (in January 2020). The move towards being a global standard started in the revision process with broadening of the industrial coverage until all industries in the business sector, including agriculture, forestry, fishing and mining, were covered by the manual.

The informal economy and the informal sector are present everywhere, but they are more relevant in developing countries. This is discussed further in Chapter 8. Measuring innovation in the informal economy is a challenge, but a necessary one if the functioning of the economy is to be understood, so that innovation policy can be developed (Kraemer-Mbula and Wunsch-Vincent 2016).

An advantage of having an international standard is that it is maintained by an organisation, in this case the OECD with Eurostat, which manages the cost of revisions and the research needed to keep the standard current. This was part of the reason why the African Union/NEPAD, at the meeting of the first Intergovernmental Meeting on Science, Technology and Innovation Indicators (Gault 2010: 139) in Mozambique, in 2007, adopted the Frascati Manual (OECD 2002) and the Oslo Manual (OECD/Eurostat 2005) as standards for R\&D and innovation surveys in Africa. These surveys led to three editions of African Innovation Outlook (AU-NEPAD 2010; NPCA 2014; AUDA-NEPAD 2019) and discussion of policy related to science and technology, and to innovation, in Africa.

To support a more inclusive and ongoing dialogue, the African Union/ NEPAD was invited in 2007 to send an observer to OECD Working Party 
of National Experts on Science and Technology Indicators (NESTI) to join the observers from RICYT in Latin America and the Caribbean, the UNESCO Institute for Statistics, and other observers from non-member countries. This resulted in contributions to discussions during the revision of the Frascati Manual (OECD 2015c) and the Oslo Manual (OECD/ Eurostat 2018) which helped make the manuals international standards.

\subsection{INNOVATION AND INTERNATIONAL STANDARDS}

Standards influence innovation. They appear in rules governing activities in countries, in international treaties, including those dealing with trade and intellectual property protection, and practices (Hawkins et al. 2017). They can be legally binding or de facto standards that communities of practice accept.

The ISO work on a standard for innovation management in its 56000 series is discussed here because it illustrates the ability of two international organisations to collaborate for the common good.

The example is the understanding of 'value'. The approach in the Oslo Manual is that adding value can be an intention of innovation but when it comes to measurement, the outcome may not have added value. The new car model may not sell, the pharmaceutical product may have unexpected and undesired outcomes and the digital product may undermine the privacy of the individual user. So long as the products are 'new or improved' and they have been 'introduced on the market' (or made available to potential users), they are innovations.

In the OECD-ISO discussions a qualifying sentence was added to the section on value. It was 'Value can be e.g. created, realized, acquired, redistributed, shared, lost, or destroyed.' This is a single illustrative example from productive discussions between the two international organisations. More can be found in Gault and Hakvåg (2018).

The work with the ISO is an example of cooperation of international organisations to ensure that their definitions are not incompatible. This raises a question about whether there should be more collaboration among international and supranational organisations to ensure that terms critical to statistical measurement and policy development, monitoring and evaluation, be used and understood in the same way. 


\subsection{CONCLUSION}

This chapter has reviewed the general definition of innovation provided in the fourth edition of the Oslo Manual (OECD/Eurostat 2018) and earlier work on general definitions (Gault 2018a) applicable in any economic sector of the SNA (Chapter 7).

While the general definition is presented in the fourth edition of the Oslo Manual, the manual has been, and still is, a guide to measuring innovation in the business sector. For that reason, the definition of innovation in the business sector has been introduced as a special case of the general definition. This allows a connection with what has gone on in earlier Oslo Manuals while maintaining the requirement that a product must satisfy a number of conditions in order to be a product innovation, including being introduced on the market.

While the guidance on measuring product innovations in the business sector in the fourth and earlier editions of the Oslo Manual is well established and understood, there is no comparable experience of changing the condition that a product be introduced on the market to being made available to potential users. Once this change is made, the implicit condition that a product introduced on the market is available at a market price is gone. Product innovations may be made available to potential users at other than economically significant prices, including zero prices. This is particularly relevant to measurement of innovation in the digital economy as there are many product innovations provided to potential users at a price of zero.

The digital economy is growing rapidly, supported by readily accessible technology. It is changing the way in which people interact with the economy and how service providers and users innovate. Given the rate of change, understanding innovation in the digital economy is a priority for the 2020s and for incorporating the outcomes into the SNA.

Digitalisation and innovation are discussed in the fourth edition of the Oslo Manual (OECD/Eurostat 2018: Section 1.2.5) where examples are provided to illustrate that digitalisation can be 'an innovation process in its own right and a key factor driving innovation'. Digitalisation can also support measurement of innovation which may not be intended as statistical measurement. Examples of this are provided in (OECD/Eurostat 2018: para. 1.53).

Restricted innovation was examined, noting that, in some cases, a single measure of innovation may not capture inclusive, or sustainable, 
or green innovation. Once the definition of innovation is restricted, and a baseline survey conducted, there may be a requirement for additional surveys to demonstrate the progress of inclusion, sustainability or growing green innovation. Subsequent surveys may be directed at people as well as at institutions.

Standards are relevant to innovation measurement and to international comparability of findings. The Oslo Manual has progressed since the first edition in 1992 from being focused on developed countries and limited in its coverage to full coverage of all institutional units in all economic sectors of the SNA in 2018. The importance of being a de facto international standard for measuring innovation and related innovation activities lies in the country comparisons that result from measurement that adheres to the standards. This was discussed in Chapter 4.

While the Oslo Manual is now an international standard, there are other international standards that influence the activity of innovation, innovation activities and framework conditions that govern the behaviour of institutional units. These influence the discourse on the subject of innovation which has a number of approaches to understanding innovation and its impact.

Now that the activity of innovation has been defined, and relevant factors considered, Chapter 7 introduces the SNA and the economic sectors where innovation happens.

\section{NOTES}

1. For more detailed discussions of the history of the definition of innovation for measurement purposes, see Smith (2005) and Gault (2013).

2 Appropriately, the proposal for the removal of the Annex came from an observer from the African Union/NEPAD at the 2016 meeting of NESTI. It was approved by delegates.

3. It is important to note that the definition of innovation in the business sector is a subset of the general definition of innovation.

4. See https://ec.europa.eu/eurostat/web/microdata/community-innovation -survey (accessed 17 March 2020).

5. The Sustainable Development Goals (SDGs) and the role of innovation in achieving them are discussed in Chapter 9.

6. See Nesta publications for discussions of inclusive innovation (https://www .nesta.org.uk, (accessed 17 March 2020).

7. See George et al. (2019) and the definition of inclusive innovation.

8. The author is indebted to Nordine Es-Sadki from UNU-MERIT for sharing the reaction of respondents from firms when asked about zero price products. That gave rise to the third condition for a product innovation that is not made available at an economically significant price. 